\title{
Glucagonoma del páncreas: la piel puede llevarnos al diagnóstico
}

\section{Pancreatic glucagonoma: observing the skin can lead to diagnosis}

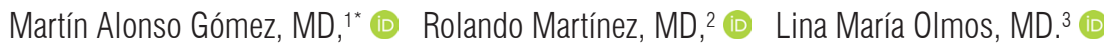

\author{
Gacceso abierto \\ Citación: \\ Gómez MA, Martínez R, Olmos LM. \\ Glucagonoma del páncreas: la piel puede \\ llevarnos al diagnóstico. Rev Colomb \\ Gastroenterol. 2020;35(3):369-371. https://doi. \\ org/10.22516/25007440.403 \\ Médico internista y gastroenterólogo, Unidad \\ de Gastroenterología y Ecoendoscopia (UGEC), \\ Hospital Universitario Nacional. Profesor \\ asociado de Medicina, Universidad Nacional de \\ Colombia; Bogotá, Colombia. \\ 2 Médico cirujano hepatobiliar, Hospital \\ Occidente de Kennedy; Bogotá, Colombia. \\ ${ }^{3}$ Médica dermatóloga, Universidad Militar Nueva \\ Granada. Dermatóloga del Dispensario Médico \\ Gilberto Echeverry Mejía; Bogotá, Colombia. \\ *Correspondencia: Martín Alonso Gómez, MD \\ martinalonsogomezz@gmail.com \\ Fecha recibido: $\quad 30 / 01 / 18$ \\ Fecha aceptado: 29/08/18
}

\section{Resumen}

Presentamos el caso de una paciente que tenía un tumor del páncreas -denominado glucagonoma- y cuyo diagnóstico se sospechó por las manifestaciones cutáneas, las cuales nos condujeron realizar una tomografía axial computarizada (TAC). En ella se halló una masa. La paciente se remitió a cirugía y presentó una buena evolución.

\section{Palabras clave}

Glucagonoma, tumores del páncreas, eritema necrolítico migratorio.

\section{Abstract}

This is a case report of a patient with a pancreatic tumor, known as glucagonoma, whose diagnosis was suspected because of skin manifestations which led to performing a CT scan, finding the mass. She underwent surgery with satisfactory results.

\section{Keywords}

Glucagonoma; Pancreatic tumor; Necrolytic migratory erythema.

\section{INTRODUCCIÓN}

Los glucagonomas del páncreas son tumores extremadamente raros, pues se presenta alrededor de un caso en un millón. Por lo general, estos tumores son grandes $(>3 \mathrm{~cm})$ y se localizan principalmente en la cola o el cuerpo del páncreas, dada la alta prevalencia de células $\alpha$ en esta área. Más del $50 \%$ son metastásicos en el momento del diagnóstico (1).

La incidencia de glucagonoma en hombres y mujeres es similar y la mayoría de los pacientes se presentan entre la quinta y sexta década de su vida. Una característica muy particular de ellos es que tienen lesiones típicas en la piel, 
cuya denominación es eritema necrolítico migratorio. Estas lesiones pueden conducir a la sospecha de dicha enfermedad como primera manifestación. Los pacientes también pueden presentar diabetes, pérdida de peso, trombosis venosa profunda (TVP) y dolor abdominal (2).

\section{OBJETIVO}

Presentar las manifestaciones clínicas de una paciente con glucagonoma y describir cómo se logró el diagnóstico de esta patología.

\section{MATERIALES Y MÉTODOS}

Se trata de una paciente de 58 años, que presentó, desde hace un año, glositis atrófica en la región centrofacial, así como placas eritematosas costrosas periorificiales en las fosas nasales y queilitis angular en las comisuras labiales (Figura 1). De igual forma, la mujer tenía placas eritematosas costrosas y pardoeritematosas en las extremidades, de crecimiento centrífugo, en diferentes estadios (algunas activas excoriadas y otras maculares con hiperpigmentación posinflamatoria) (Figura 2).

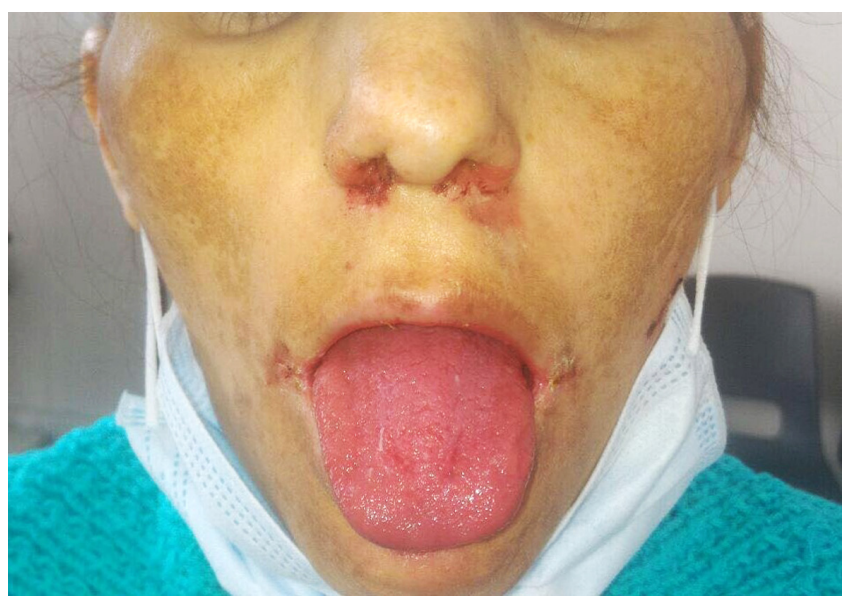

Figura 1. Se observan tanto la queilits angular como las placas eritematosas costrosas periorificiales.

Se observó la diferencia del diámetro de las piernas, secundario a una trombosis profunda. Después, la paciente desarrolló anemia y diabetes. Por tanto, se realizaron múltiples estudios, sin identificar la causa de la trombosis. Cuando la mujer presentó pérdida de peso, acompañada de dolor abdominal, fue remitida a nuestra unidad. Durante este período solo recibió corticoides tópicos para sus lesiones y terapia oral para el control de su diabetes. En consecuencia, realizamos una TAC y encontramos una gran masa en la cola del páncreas (Figura 3), así como una metástasis de $2 \mathrm{~cm}$ en el hígado. Ante la sospecha de un glucagonoma, solicitamos un glucagón sérico, el cual fue elevado. Por tal razón, la mujer fue conducida a cirugía y allí se practicó una pancreatectomía distal (Figura 4), con control de sus lesiones en la piel y de su diabetes. La patología confirmó la existencia del glucagonoma y la paciente continuó, un año después, en el manejo con quimioterapia, lo que generó una buena respuesta.

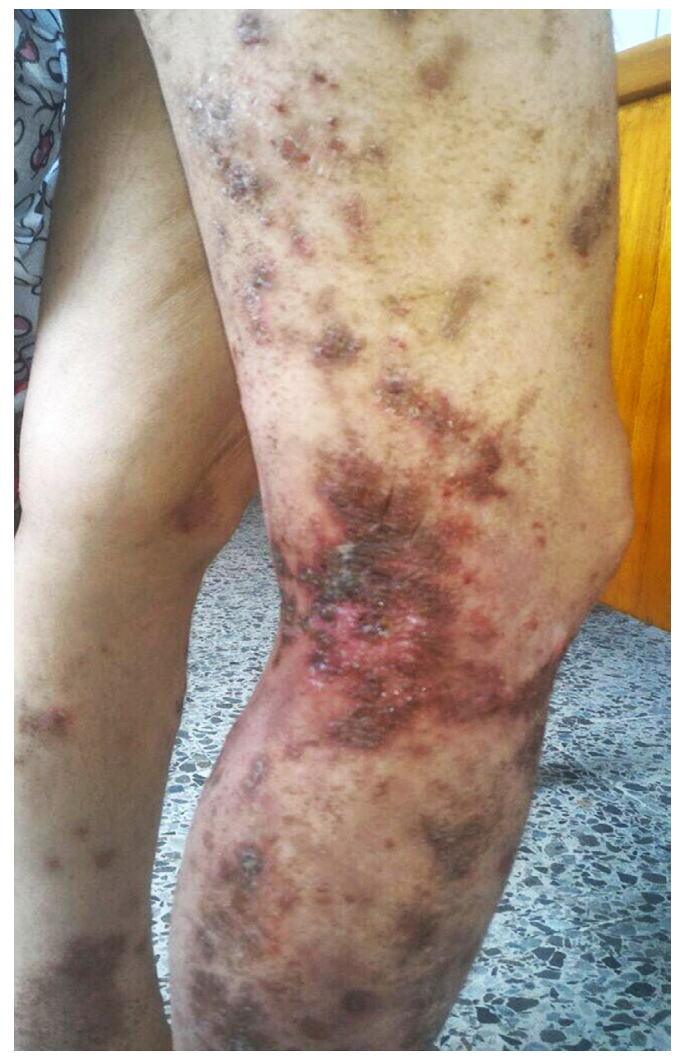

Figura 2. Se presentaron placas eritematosas costrosas y pardoeritematosas en las extremidades.

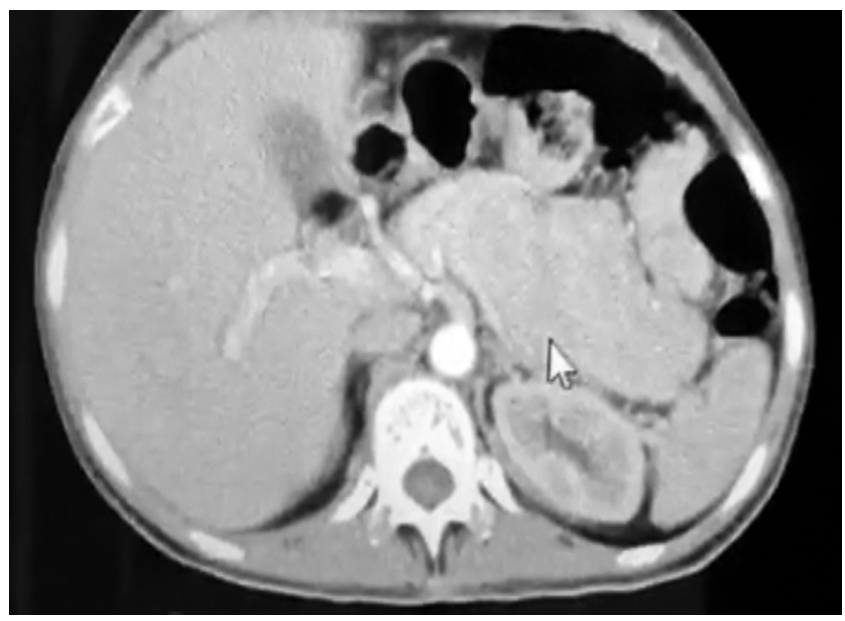

Figura 3. La flecha señala una gran masa en la cola del páncreas, que desplaza al riñón izquierdo. 


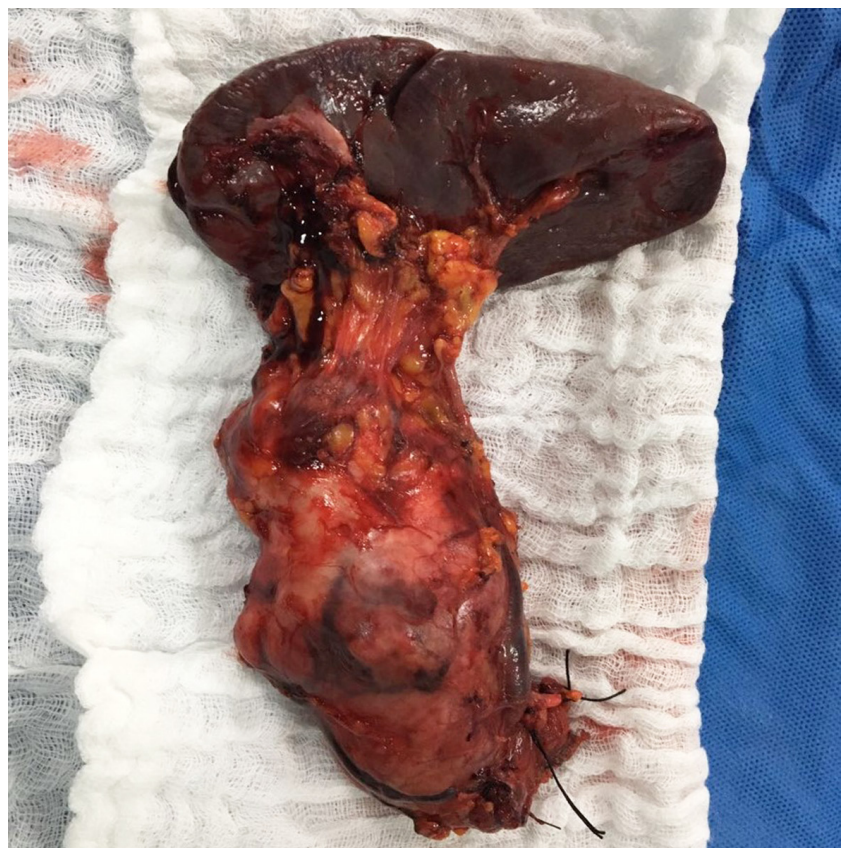

Figura 4. Se observa la pieza quirúrgica de la masa en la cola del páncreas, que incluyó una esplenectomía.

Los glucagonomas fueron descritos por primera vez en 1942 por Becker y colaboradores. Estos autores presentaron un caso, muy similar al nuestro, de una mujer de 45 años con lesiones mucocutáneas, asociadas con una prueba de tolerancia a la glucosa alterada. En la autopsia de la paciente se encontró una masa en el páncreas (3).

Sin embargo, fue el Dr. McGavran, quien en 1966 describió los síntomas típicos de la enfermedad, los cuales se caracterizaron por la presencia de una dermatitis asociada a los niveles elevados de glucagón, dado que son tumores neuroendocrinos que se originan en las células madre pluripotenciales endodérmicas y surgen de las células $\alpha$ de los islotes en el páncreas (4-7).

La mayoría de los glucagonomas son solitarios; sin embargo, menos del $10 \%$ de ellos se han asociado con el síndrome de neoplasia endocrina múltiple 1 (NEM1). En nuestro caso, este síndrome se descartó (8).

\section{CONCLUSIÓN}

El glucagonoma es un tumor muy raro, razón por la cual se sospecha poco. Nuestro caso muestra que las lesiones en la piel habrían podido conducir a un diagnóstico más temprano, pues el eritema necrolítico migratorio que se confirmó en la patología de la paciente es típico de la enfermedad. Esto está asociado a la TVP, a la diabetes, a la anemia y a la pérdida de peso, que son las 5 características típicas que nos deben hacer sospechar de la presencia de este tumor pancreático. $\mathrm{Si}$ se detecta a tiempo, tiene muy buen pronóstico.

\section{REFERENCIAS}

1. Sarr MG, Murr M, Smyrk TC, Yeo CJ, Fernández-delCastillo C, Hawes RH, Freeny PC. Primary cystic neoplasms of the pancreas. Neoplastic disorders of emerging importance-current state-of-the-art and unanswered questions. J Gastrointest Surgí. 2003;7(3):417-28. http://doi.org/10.1016/s1091-255x(02)00163-4

2. Adsay NV. Cystic neoplasia of the pancreas: pathology and biology. J Gastrointest Surg. 2008;12(3):401-404. http://doi.org/10.1007/s11605-007-0348-z

3. Braverman IM. "Cutaneous manifestations of internal malignant tumors" by Becker, Kahn and Rothman, June 1942. Commentary: Migratory necrolytic erythema. Arch Dermatol. 1982;118(10):784-798. http://doi.org/10.1001/archderm.118.10.784

4. McGavran MH, Unger RH, Recant L, Polk HC, Kilo C, Levin ME. A glucagon-secreting alpha-cell carcinoma of the pancreas. N Engl J Med. 1966;274(25):1408-1413. http://doi.org/10.1056/NEJM196606232742503
5. Yao JC, Eisner MP, Leary C, Dagohoy C, Phan A, Rashid A, Hassan M, Evans DB. Population-based study of islet cell carcinoma. Ann Surg Oncol. 2007;14(12):3492-500. http://doi.org/10.1245/s10434-007-9566-6

6. Kindmark H, Sundin A, Granberg D, Dunder K, Skogseid B, Janson ET, Welin S, Oberg K, Eriksson B. Endocrine pancreatic tumors with glucagon hypersecretion: a retrospective study of 23 cases during 20 years. Med Oncol. 2007;24(3):330-7. http://doi.org/10.1007/s12032-007-0011-2

7. Tierney EP, Badger J. Etiology and pathogenesis of necrolytic migratory erythema: review of the literature. MedGenMed. 2004;6(3):4.

8. van Beek AP, de Haas ER, van Vloten WA, Lips CJ, Roijers JF, Canninga-van Dijk MR. The glucagonoma syndrome and necrolytic migratory erythema: a clinical review. Eur J Endocrinol. 2004;151(5):531-537. http://doi.org/10.1530/eje.0.1510531 